\title{
Editorial
}

Dermatology

\section{Classification of Polygenic Inflammatory Diseases Distributed along the Lines of Blaschko}

\section{Dan Lipsker Cédric Lenormand}

Faculté de Médecine, Université Louis Pasteur et Clinique Dermatologique des Hôpitaux Universitaires, Strasbourg, France

In this issue of Dermatology, Boente et al. [1] report an 8 -year-old boy with juvenile dermatomyositis who developed Blaschko-linear bands of calcification on the left lower limb. We follow up a patient with similar clinical findings. At the age of 12 years he developed Blaschkolinear lines of calcified nodules on the lower limb (fig. 1) for which he consulted. On examination he was found to have typical signs of dermatomyositis (fig. 2).

Boente et al. discuss the possibility that loss of heterozygosity could explain this unusual segmental manifestation of dermatomyositis, by analogy to what has been described under the designation of type 2 segmental manifestations in monogenic diseases [2]. In thelatter situation, this mechanism has been proven, as for example in Hailey-Hailey disease [3]. The rationale of this assumption is as follows. If the effect of a pathologic gene that would predispose to a specific disease, for instance dermatomyositis, is not balanced by the effect of the normal gene inherited from the other parent, its effect will be increased. Therefore, in cells where only the pathologic gene is present, either homozygous or hemizygous, the disease expression will be enhanced. However, direct evidence of this mechanism in polygenic inflammatory diseases is missing. Mosaicism has been proved only once in a patient with adult-onset blaschkitis [4]. One of Boente's co-authors, Rudolf Happle, has been the leading investi- gator for over 30 years in the field of the nosology of Blaschko-linear diseases. He recently introduced the concept of 'superimposed segmental manifestation' to describe severe segmental involvement in polygenic diseases [5], since the designation 'type 2 segmental manifestation' should be restricted to diseases with monogenic mendelian inheritance. Indeed, it is (yet) not possible in polygenic diseases to distinguish between type 1 segmental manifestations, which reflect heterozygosity for a post-zygotic new mutation occurring in an otherwise healthy individual, and type 2 segmental manifestations. We are currently working on a comprehensive classification of polygenic inflammatory diseases distributed along the lines of Blaschko, and we reviewed the cases that were managed in our department during the past 10 years [6]. We think that Happle's proposal should be expanded and that 4 conceptually different situations need to be individualized in order to classify polygenic inflammatory diseases along the lines of Blaschko.

In type 1, disease involvement occurs exclusively along the lines of Blaschko.

Obviously, this can never be ascertained, since the patient can develop involvement outside the lines of Blaschko in the future. However, in the case of inflammatory diseases exclusively localized along the lines of Blaschko, 2 situations need to be individualized.

\section{KARGER}

Fax +4161306 1234

E-Mail karger@karger.ch

www.karger.com (c) 2009 S. Karger AG, Basel

$1018-8665 / 09 / 2192-0099 \$ 26.00 / 0$

Accessible online at:

www.karger.com/drm
D. Lipsker

Clinique Dermatologique, Hôpitaux Universitaires

1 , place de l'hôpital

FR-67091 Strasbourg Cedex (France)

Tel. +33 388116 179, Fax +33 388115 962, E-Mail dan.lipsker@chru-strasbourg.fr 
1

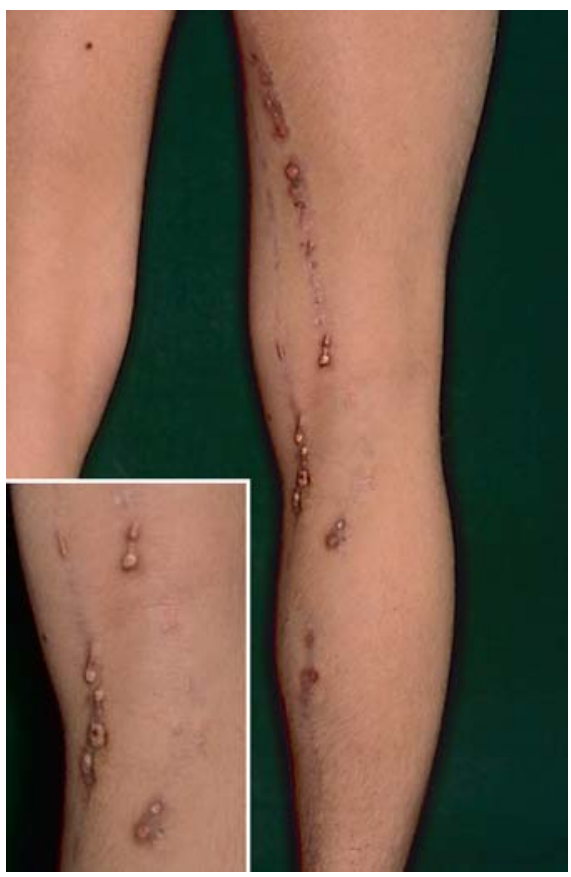

2

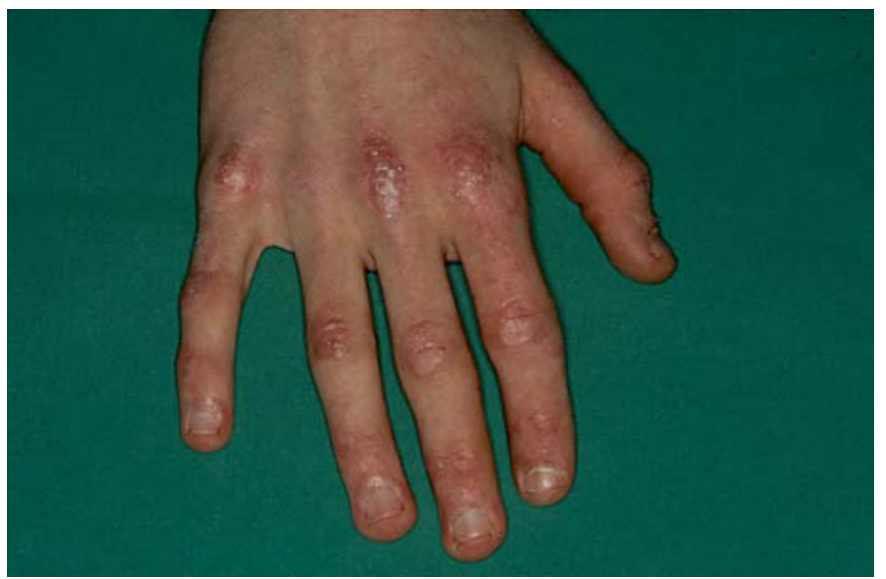

Fig. 1. Calcified nodules along the lines of Blaschko.

Fig. 2. Gottron papules, cuticular necrosis and periungueal telangiectasis (capillary loops) typical of dermatomyositis.
In type $1 a$, an equivalent manifestation with a nonsegmental distribution exists, and it is usually even much more common than the Blaschko-linear involvement, as for example in lichen planus.

In type $1 b$, the disease is (provisionally) defined by its Blaschko-linearity, and the non-Blaschko-linear equivalent is not known or does not exist, as for example in lichen striatus or in adult-onset blaschkitis.

In type 2, Blaschko-linear involvement of the disease, and other, non-Blaschko-linear, manifestations occur simultaneously or successively. The latter can be either of the following.

Type $2 a$ refers to skin involvement of the same type as the one which is Blaschko-linear, as for example in psoriasis.

Type $2 b$ includes other clinical and/or biological manifestations of the disease, occurring either on the skin or in any other organ system, as for example Blaschko-linear cutaneous lupus erythematosus in a patient with other clinical or biological signs of lupus erythematosus.

It is generally not possible to match a peculiar disease with one of these types in an exclusive way, as psoriasis for example, depending on the patient, can occur as a type $1 \mathrm{a}$, type $2 \mathrm{a}$ or type $2 \mathrm{~b}$ manifestation. It will be type la if it is only Blaschko-linear. It can be classified as type 2a if it occurs in both usual and Blaschko-linear distribution. Rarely, it can be a type $2 \mathrm{~b}$ manifestation, as for example in a patient with Blaschko-linear psoriasis and typical psoriatic arthropathy. We have seen examples of those 3 situations in our practice [6]. In case of polygenic inflammatory diseases, the mere existence of type la can be questioned. However, from a conceptual point of view this classification has some advantages, as it is descriptive and sign- and not disease-based.

Let us now turn back to the 2 boys with dermatomyositis. They had Gottron papules, telangiectases and atrophy on their hands, and calcification along the lines of Blaschko on a lower limb. They would therefore be best classified as type $2 \mathrm{~b}$. If the loss of heterozygosity theory is correct, this means that each sign - calcinosis and Gottron papules - has its own genetic signature, at least in this disease. The polygenetic predisposition to calcinosis is not the same as the one predisposing to poikiloderma or to Gottron papules. In the era of genomewide screening and molecular pathology, we will probably be able to decipher the genetic background underlying these different clinical signs in the coming years. It is therefore more important than ever to precisely characterize the clinical phenotype, because only a precise assessment of the clinical phenotype will confer meaning to the genetic findings. 
References

Classification of Polygenic Inflammatory Diseases along the Lines of Blaschko
1 Boente MC, Nadra G, Asial R, Happle R: Pronounced linear calcinosis in a boy with mild dermatomyositis. A further possible example of superimposed segmental manifestation of a polygenic disorder. Dermatology 2009;219:155-157.

-2 Happle R: Segmentale Typ-2-Manifestation autosomal dominanter Hautkrankheiten: Entwicklung eines neuen formalgenetischen Konzeptes. Hautarzt 2001;52:283-287.

3 Poblete-Gutierrez P, Wiederholt T, König A, Jugert FK, Marquardt Y, Rübben A, Merk HF, Happle R, Frank J: Allelic loss underlies type 2 segmental Hailey-Hailey disease, providing molecular confirmation of a novel genetic concept. J Clin Invest 2004;114:14671474.
4 Lipsker D, Cribier B, Girard-Lemaire F, Flori E, Grosshans E: Genetic mosaicism in an acquired inflammatory dermatosis following the lines of Blaschko. Arch Dermatol 2000; 136:805-807.

5 Happle R: Superimposed segmental manifestation of polygenic disorders. J Am Acad Dermatol 2007;57:690-699.

6 Lenormand C: Dermatoses inflammatoires blaschkolinéaires de l'adulte (thèse de médecine 64). Strasbourg, Université Louis Pasteur, 2008. 